Document downloaded from:

http://hdl.handle.net/10251/49341

This paper must be cited as:

Lujan Martinez, JM.; Climent Puchades, H.; Olmeda González, PC.; Jimenez Macedo, VD. (2014). Heat transfer modeling in exhaust systems of high-performance two-stroke engines. Applied Thermal Engineering. 69(1-2):96-104.

doi:10.1016/j.applthermaleng.2014.04.045.

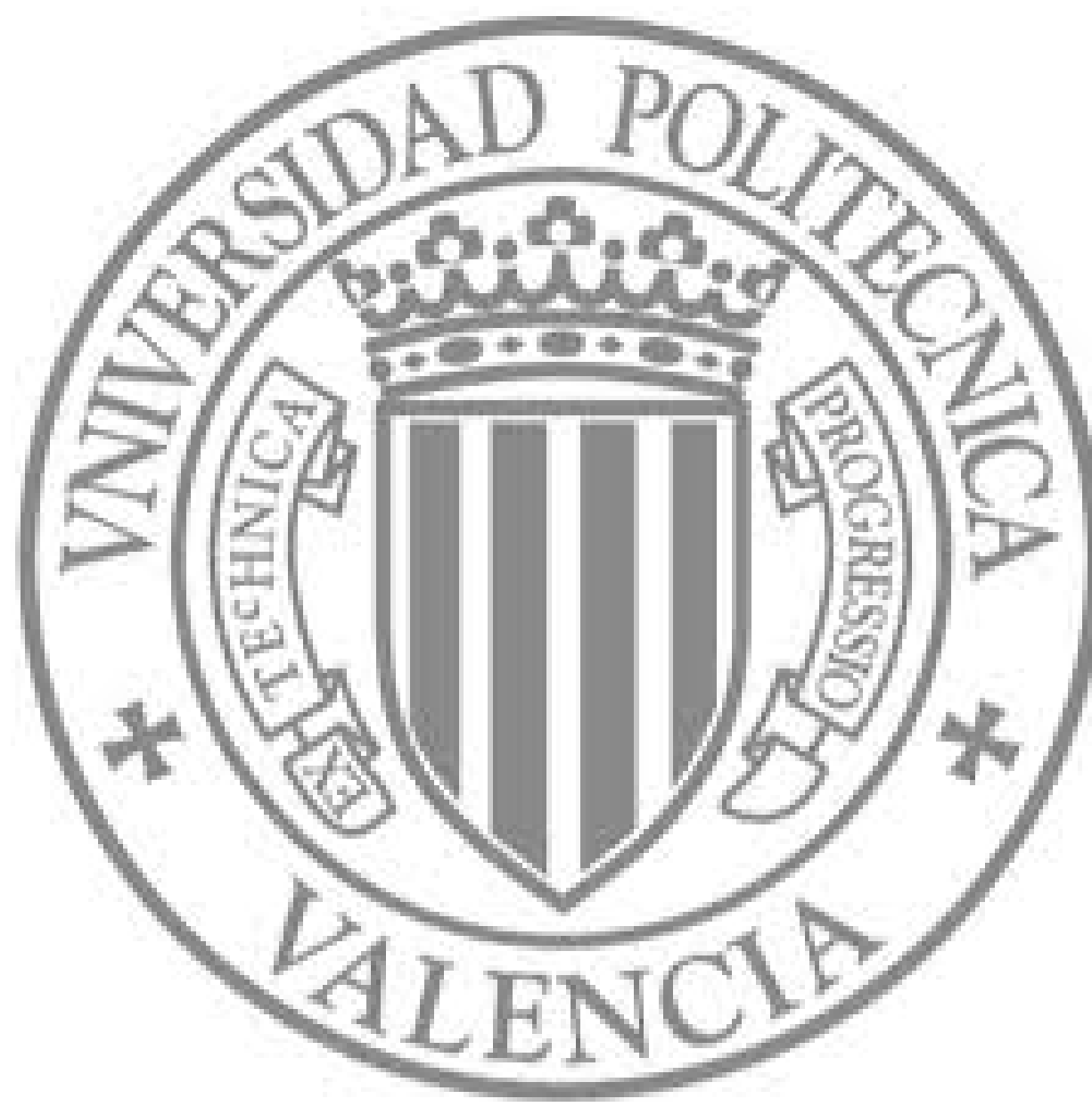

The final publication is available at

http://dx.doi.org/10.1016/j.applthermaleng.2014.04.045

Copyright Elsevier 


\section{HEAT TRANSFER MODELLING IN EXHAUST SYSTEMS OF HIGH-PERFORMANCE TWO-STROKE ENGINES}

José Manuel Luján, Héctor Climent*, Pablo Olmeda, Víctor Daniel Jiménez

CMT Motores Térmicos, Universitat Politècnica de València, Spain

* Corresponding author. Postal address: CMT Motores Térmicos, 2o Edificio de Investigación. Universitat Politècnica de València. Camino de Vera s/n. 46022. Valencia. Spain.

\section{ABSTRACT}

Heat transfer from the hot gases to the wall in exhaust systems of high-performance two-stroke engines is underestimated using steady state with fully developed flow empirical correlations. This fact is detected when comparing measured and modelled pressure pulses in different positions in the exhaust system. This can be explained taking into account that classical expressions have been validated for fully developed flows, a situation that is far from the flow behaviour in reciprocating internal combustion engines. Several researches have solved this phenomenon in four-stroke engines, suggesting that the unsteady flow is strongly linked to the heat transfer. This research evaluates the correlations proposed by other authors in four stroke engines and introduces a new heat transfer model for exhaust systems in two-stroke, high performance, gasoline engines. The model, which accounts for both the entrance length effect and flow velocity fluctuations, is validated against experimental measurements. Comparisons of the proposed model with other models are performed, showing not negligible differences in the scavenge process related parameters.

Keywords: heat transfer, unsteady flow, 1D modelling, two-stroke engine

\section{INTRODUCCION}

In comparison with four-stroke engines, the wave propagation phenomena inside the exhaust system in two-stroke engines is even more critical because of its influence in the cylinder scavenging process, which determines the residual gases and trapped mass for the next engine cycle. The instantaneous pressure in the exhaust system depends basically on the in-cylinder thermodynamic conditions, the opening speed of the exhaust port, the geometry of the exhaust 
system and the heat transfer through the exhaust system [1]. Thus, heat transfer modelling in exhaust systems is an important issue if accurate engine simulations are desired. The use of conventional models to reproduce the heat transfer loss from the hot gases to the wall in exhaust systems of high-performance two stroke engines usually leads to underestimate the phenomenon.

This is shown in the wave propagation delays between the modelled and measured instantaneous exhaust pressure pulses as Fig. 1 depicts. These results are obtained in a $125 \mathrm{cc}$ two-stroke engine at $12500 \mathrm{rpm}$ and full load. The cylinder blow-down is observed, in both measured and calculated pressure traces, by a rapid increase in the exhaust pressure when the exhaust port is opened (at 100 crank angle degree). This pressure pulse travels through the exhaust system at the local sound speed, which depends on the gas temperature and, hence, the heat transfer to the walls. It is observed that the pressure pulses originated by the exhaust system geometry travel faster in the calculated instantaneous pressure when using the DittusBoelter correlation [2] for the estimation of the convection heat coefficient.

For the heat transfer modelling in reciprocating internal combustion engines, correlations for fully developed turbulent flow, type $\mathrm{Nu}=f(\operatorname{Re}, \mathrm{Pr})$, are used. Among them, the classic expressions developed by Dittus-Boelter [2], Sieder-Tate [3] and Huber [4] are the most used. Several researchers modelled the heat transfer in exhaust manifolds and pipes based on classical expressions but re-calibrating their parameters [5-8].

However, in unsteady processes, those correlations are improved with dimensionless coefficients to calculate the heat transfer in straight exhaust manifolds in four-stroke engines. This phenomenon is modelled taking account: (i) the entrance effects of the flow blown from the cylinder together with the development of the turbulence along the pipes [9-13], and (ii) the highly unsteady flow with rapid velocity variations, which are not negligible [14].

The main objectives of this research are: first the evaluation and applicability of general empirical heat transfer models in exhaust systems for high-performance two stroke engines and, the introduction of a new heat transfer model more suitable for these engines. The proposed model, which is added to a $1 \mathrm{D}$ engine simulation code, takes into account the entrance phenomena and the highly unsteady flow inside the exhaust system. In order to verify that the wave phenomena are reproduced with good accuracy, the instantaneous pressure 
traces in different parts of the exhaust system and the gases mass flow through the engine are compared. In a next step, the engine model can be used to obtain and analyze the scavenging coefficients. Thus, the thermo-and fluid dynamic variables that characterize the engine performance are calculated.

The paper is structured as follows. First, in section 2, the one-dimensional engine model and the development of the proposed heat transfer model are presented. Then, in section 3 , the experimental methodology that will be used to calibrate and validate the proposed model is described. After that, the calibration parameters that define the explored models are shown in section 4. The results of the evaluation and validation of heat transfer model proposed is the subject of section 5. Moreover, in this section, the results obtained are contrasted with experimental measurements and compared with other models found in the literature. Finally, the main conclusions of this research are presented.

\section{MODEL DEVELOPMENT}

\section{$2.11 \mathrm{D}$ engine model}

Wave propagation phenomena during gas exchange processes inside internal combustion engines are assumed to be one dimensional. In the case under consideration, a wave action model, which solves the unsteady, non linear and one dimensional flow equations using a finite difference scheme [15], is used to model the high performance two stroke engine.

Fig. 2 shows a schematic layout of the $125 \mathrm{cc}$ engine. As depicted in this figure, it is observed that the engine is composed basically of three kinds of elements: ducts (1D), volumes (OD) and junctions (J). Volumes (such as cylinder, crankcase, airbox and atmosphere) are calculated using a zero dimensional approach, by solving mass and energy conservation equations. In-cylinder heat release rate for combustion simulation is obtained by means of correlations for Wiebe function parameters [16].

Effective area of junctions (such as exhaust and transfer ports, rotating disk or reed valves) between ducts and volumes are solved by means of a discharge coefficient, which has to be previously obtained in a steady flow bench. Boundary conditions are solved using the method of characteristics and then coupled with the finite difference calculation in the ducts [17]. Exhaust 
systems, silencer and airbox were characterized in an impulse test rig [18]; subsequently they were simulated individually with the 1D code, for later setup of the complete geometry.

The governing equations that describe the one dimensional non homentropic gas flow, with the consideration of transversal section change, friction and heat transfer in a pipe, form a non homogenous hyperbolic system, and are represented in vector notation as Daneshyar [19]:

$\frac{\partial \mathbf{W}}{\partial t}+\frac{\partial \mathbf{F}}{\partial x}+\mathbf{C}_{1}+\mathbf{C}_{2}=0$

This conservation law system, comprising the continuity, momentum and energy equations, is complemented by the equation of state or the real gas properties [20]. In Eq. (1), W is the desired state vector of the solution, $\mathbf{F}$ is the flux vector and $\mathbf{C}$ the source term separating the effect of the area changes from the effect of friction and heat transfer. The one dimensional gas flow governing equations was traditionally arranged in the vector form shown in Eq. (2):

$$
\begin{aligned}
& \mathbf{W}(x, t)=\left[\begin{array}{c}
\rho \\
\rho u \\
\rho \frac{u^{2}}{2}+\frac{p}{\gamma-1}
\end{array}\right] \quad \mathbf{F}(\mathbf{W})=\left[\begin{array}{c}
\rho u \\
\rho u^{2}+p \\
u\left(\rho \frac{u^{2}}{2}+\frac{\gamma p}{\gamma-1}\right)
\end{array}\right] \\
& \mathbf{C}_{1}(x, \mathbf{W})=\left[\begin{array}{c}
\rho u \\
\rho u^{2} \\
u\left(\rho \frac{u^{2}}{2}+\frac{\gamma p}{\gamma-1}\right)
\end{array}\right] \frac{1}{S} \frac{d S}{d x} \quad \mathbf{C}_{2}(\mathbf{W})=\left[\begin{array}{c}
0 \\
g \rho \\
-q \rho
\end{array}\right]
\end{aligned}
$$

This set of equations is solved by using the TVD method [21], which is programmed in the computer code together with the boundary conditions.

The scavenge process inside the cylinder is an important issue in two-stroke engines. A well-known model [22] to account for short circuit phenomenon was used in the present study. This type of models allow the estimation of scavenge related parameters, such as: delivery ratio, scavenge efficiency and trapping efficiency. Fig. 3 illustrates the classical representation for scavenge evaluation. The delivery ratio is the relation between the measured mass through the intake system, $m_{\text {supplied, }}$ and the mass that ideally would enter into the cylinder taking into account the engine displacement and the density at some reference conditions, $m_{\text {ref. }}$ The scavenging efficiency is the ratio between the fresh mixture trapped in the cylinder, $m_{\text {trapped }}$, and the total mass in the cylinder for the next engine cycle, $m_{\text {charge. }}$ Therefore, the scavenging efficiency evaluates the residuals that remain inside the cylinder from the previous cycle. The 
trapping efficiency evaluates the short-circuit phenomenon and is calculated with the fresh mixture trapped in the cylinder, $m_{\text {trapped}}$, divided by the intake mass, $m_{\text {supplied. }}$.

\subsection{Heat transfer model}

From the different models that account for the turbulence decay found in the literature [9-13], an example is the one proposed by Farrugia [11], where the Nusselt number is corrected with the following parameter:

$\psi=1+\frac{C_{1} \operatorname{Re}^{d}}{(x / D)}$

where $C_{l}$ and $d$ are calibration constants, $x$ is the distance from the calculation node to the exhaust port, $D$ is the exhaust valve diameter and Re the cycle-average Reynolds number calculated in the exhaust valve. Using empirical data from partial and full load conditions from 1000 to $4000 \mathrm{rpm}$ in a 4-stroke spark-ignited engine, Farrugia proposes 0.075 and 0.25 , for $C_{I}$ and $d$ respectively.

The model developed by Zeng [14] takes into account flow velocity fluctuations in the heat transfer coefficient determination. The correction to the Nusselt number is given by:

$\psi=\left(1+C_{2} \frac{D}{u^{2}}\left|\frac{\mathrm{d} u}{\mathrm{~d} t}\right|\right)^{b}$

where $C_{2}$ and $b$ are calibration constants, $u$ is the gas particle velocity and $D$ is the valve diameter.

The proposed model in this paper takes into account the two described phenomena: on one side, the entrance length and turbulence decay from the exhaust port section, and, on the other side, the velocity fluctuation of the flow. The former is estimated by using the distance from the calculation node, $x$, to the exhaust port cross section. The latter is determined by computing the variation of the velocity in the calculation node with time, $\mathrm{d} u / \mathrm{d} t$. A new dimensionless number derived from the multiplication of both terms, also in non-dimensional approach, is proposed:

$\Phi=\left(\frac{1}{x / D}\right)\left(\frac{D}{u^{2}}\left|\frac{\mathrm{d} u}{\mathrm{~d} t}\right|\right)$

where $x$ is the distance from the calculation node to the exhaust port, $u$ is the gas particle velocity and $D$ is the diameter in the considered cross section. As it is observed, the first 
parenthesis in Eq. (5) is related to the entrance length effects, since calculation nodes close to the exhaust port provide higher values of $\Phi$. In the same way, a high velocity fluctuation, which is accounted in absolute value in the second parenthesis, lead to higher values of $\Phi$ as well. The combination of the two effects is important for the model calibration and assessment. The multiplication of the two parentheses in Eq. (5) means that the model will not capture the turbulence decay effect in a situation where there is not velocity fluctuation and vice versa. However, this model description has not limited the results as it will be later demonstrated.

Based on the Reynolds analogy, which relates the friction coefficient with dimensionless numbers of Stanton, Nusselt, Reynolds and Prandtl, and using the Chilton-Colburn analogy, the proposed model by Dittus-Boelter can be obtained [2]. If the proposed dimensionless number in Eq. (5) is included in this expression we get:

$$
\mathrm{Nu}_{\Phi}=0.023 \operatorname{Re}^{0.8} \operatorname{Pr}^{0.33}\left(1+V_{1} \frac{D^{2}}{x u^{2}}\left|\frac{\mathrm{d} u}{\mathrm{~d} t}\right|\right)^{V_{2}}
$$

where $V_{1}$ and $V_{2}$ are two calibration constants obtained experimentally. With the proposed Nusselt number correction, Eq. (6) can be applied anywhere in the exhaust system, and it is valid for both steady and pulsating flow.

The parameter $q$ shown in Eq. (2), concerning the energy conservation equation inside the duct, represents the heat power per unit of mass flow and it is a source term in the partial differential equations system that is obtained using:

$$
q=\frac{\dot{Q}}{\dot{m}}
$$

where $\dot{m}$ represents the mass flow through the mesh and $\dot{Q}$ is obtained using Newton's law of cooling, since radiation heat transfer is neglected:

$$
\dot{Q}=h_{\Phi} \pi D \Delta x\left(T_{g}-T_{w}\right)
$$

where $h_{\Phi}$ is the unsteady heat transfer coefficient, $\Delta x$ is the spatial mesh length (distance between calculation nodes), $T_{g}$ the gas temperature and $T_{w}$ the inner wall duct temperature.

The inner wall duct temperature is assumed to be very similar to the outer wall duct temperature due to two reasons: (i) the reduced thickness of the sheet of exhaust system $(2 \mathrm{~mm})$, and (ii) the high thermal conductivity of the material. The external wall temperature is obtained 
experimentally using an infrared thermal camera, which allows estimating the temperature distribution along the exhaust system. This measured temperature profile is an input to the engine simulation.

The local convection coefficient is obtained using the corrected Nusselt number defined in Eq. (6) and the following expression:

$h_{\Phi}=\frac{\mathrm{Nu}_{\Phi} k}{D}$

where $k$ is the fluid thermal conductivity, which is assumed to be similar to the air.

\section{EXPERIMENTAL SETUP}

A two-stroke engine, whose main features are shown in Table 1, was employed in the present study. The engine is a spark-ignited, crankcase-scavenged type and single-cylinder engine traditionally used in racing applications. A test bench, shown schematically in Fig. 4, was fully instrumented to carry out performance measurements. Main measurement devices consisted of an eddy-current electric brake (up to $175 \mathrm{~kW}$ ), a hot wire anemometer to measure the air mass flow entering the engine and a gravimetric balance to register the fuel consumption.

Firing tests were carried out at different load and engine speed conditions, since an electronic module controlled the brake as well as the throttle position. The engine has liquid cooled cylinder, therefore a second cooling system was designed in order to control the engine coolant temperature.

Fluid flow properties are also relevant in checking the accuracy of the model. Cycle average temperature and pressure were measured at the intake and exhaust pipes with thermocouples and manometers. Also, the external wall temperature was captured with an infrared camera [23] to aid the 1D engine model. Moreover, pressure transducers were placed in the cylinder, crankcase, and exhaust port in order to measure its instantaneous evolution (every 0.5 crank angle degree) following the indications given in [24].

Fig. 5 shows the pressure traces for 25 consecutive engine cycles at a certain engine operating condition. Measurements are acquired inside the cylinder (top plot), in the crankcase (middle plot) and in the exhaust system close to the exhaust port (bottom plot), where 0 cad represents the top dead centre of the piston. For the presented study, it is important to remark that pressure evolutions in the exhaust system do not show the in-cylinder cycle-to-cycle variation, 
which is typical of spark-ignited engines [25]. This is due to the fact that the in-cylinder pressure after the combustion process collapses into very similar expansion lines, and in-cylinder conditions are comparable at the exhaust port opening angle. This behaviour is checked for all engine running conditions presented in this research.

Concerning the exhaust instantaneous pressure, it is detected a sudden increase after 90 cad, due to the cylinder blow down when the exhaust port opens. The generated pressure pulse travels through the exhaust system and reflects as depression waves in a first stage when evolving inside the divergent pipe, and as overpressure waves when the convergent pipe is encountered. These depression and overpressure waves travel back to the cylinder and are clearly detected by the pressure measurement (at 150 and 240 cad respectively, in the plotted engine running condition). The exhaust pressure evolutions always follow the described pattern and, if synchronised properly, help to extract the exhaust gases from the cylinder at the beginning of the scavenge process and retain the fresh mixture before closing the exhaust port. The instantaneous pressure plotted in the crank-angle domain depends mainly on the engine speed. Although wave propagation phenomena are modified by the sound speed, exhaust gases temperature does not change largely within tested engine conditions. Therefore, engine performance relies very much on the design of the so-called tuned exhaust system geometry and engine speed.

Fig. 6 represents a schematic layout of the exhaust system, where basic geometrical data are given. Exhaust system pressure evolutions are acquired in three locations along the exhaust system. The distances from the exhaust port are: 200, 349 and $471 \mathrm{~mm}$. The choice of these points is not arbitrary: transducer \#1 was placed in a point very close to the exhaust port and, therefore, it is very important from the unsteady flow behaviour point of view. Moreover, this transducer is placed in the first third of the divergent pipe, where the reflected pulses are generated. Transducer \#2 was positioned in the second third of the divergent duct of the exhaust system. Finally, transducer \#3 was placed in the straight pipe between the divergent and convergent cones of the exhaust system, where the diameter is the largest. Therefore, the amplitude of the pressure pulses is low due to the large cross section value.

\section{MODELS CALIBRATION}


Different heat transfer models are compared in order to evaluate their behaviour and show their main advantages and disadvantages. Three models were calibrated in the simplest geometry of an exhaust system: a constant cross section duct. In this way, modelling uncertainties related to cross section variations are avoided. Therefore, the experimental setup consists of a straight duct as exhaust system (39.35 mm in diameter and $458 \mathrm{~mm}$ in length) equipped with piezoelectric and piezoresistive pressure transducers. These are placed on two different sections, located at 100 and $230 \mathrm{~mm}$ from the exhaust port respectively. Besides, average gas and wall temperatures are measured at the same points by means of K-type thermocouples.

This exhaust system allows engine testing under a wide range of operating conditions between 7000 and $11000 \mathrm{rpm}$. Engine operation was not steady enough outside these engine speeds since pressure wave propagation phenomena configure a poor scavenge process with high concentration of residual gases inside the cylinder, which promoted misfire events.

The straight exhaust system geometry is incorporated in the previously described 1D engine model, where the following heat transfer models for the exhaust systems are tested: (i) Farrugia [11], related to the turbulence decay and governed by Eq. (3), (ii) Zeng [14], which accounts for the flow velocity fluctuations and controlled by Eq. (4), and (iii) the proposed model shown in Eg. (6).

The calibration of the constants in the models, gathered in Eqs. (3), (4) and (6), is performed by means of engine simulations. Simulations were run from 7000 to $11000 \mathrm{rpm}$ every $500 \mathrm{rpm}$. Each steady state engine running condition was tested with the three heat transfer models. Each heat transfer model has two calibration constants, which were modified according to the values given in Table 2. A comparison between calculated and measured exhaust instantaneous pressure is performed for model assessment. Pressure evolutions at transducer \#1 location are analyzed since it is the most critical point for the evaluation of the heat transfer in the exhaust system. Fig. 7 shows an example of this comparison at $10500 \mathrm{rpm}$, where the calculated pressure evolutions in the three models for a given set of calibration constants are plotted against the measured data. The points in the upper right zone of each plot represent the cylinder blow down when the exhaust port opens. On the contrary, the points in the lower left zone of the graph correspond to the cylinder scavenge process or when the exhaust port is 
closed. It is observed that a representation of the results as Fig. 7 shows is not useful to provide a good quality analysis for models comparison.

The coefficient of determination $\left(R^{2}\right)$ between measured and calculated data in transducer \#1 location seems to be an appropriate parameter to quantify the model prediction. Fig. 8 shows the results in terms of $R^{2}$ obtained from the simulation matrix given in Table 2, at $10500 \mathrm{rpm}$, where the optimum values for the calibration constants are found. Other correlations for the turbulence decay modelling found in the literature previously referenced were also evaluated but, after recalibration of their constants values, the results provided similar or less accurate predictions than Farrugia's correlation.

If Farrugia's model calibration constants, $C_{l}$ and $d$, are set to 1.5 and 0.25 , there is an optimum in the coefficient of determination at $10500 \mathrm{rpm}$, as depicted in the bottom plot. In the middle plot, it is observed that Zeng's model calibration constants, $C_{2}$ and $b$, are not easily defined by a pair of values. The optimum values resemble very much to the shape of an equilateral hyperbola, which means that high $\mathrm{R}^{2}$ values are obtained with low $b$ and high $C_{2}$ values or vice versa. If $b$ value is set to 0.8 , as proposed by Zeng, the value for $C_{2}$ must be 2 in order to maximize $\mathrm{R}^{2}$. Values for the proposed model are presented in the upper plot, where $V_{1}$ and $V_{2}$ should be set to 7 and 0.8 respectively. Overall, by looking at the colour-bar of the three plots, it is detected that all the models provide good quality values for the coefficient of determination. For brevity reasons, only the results at $10500 \mathrm{rpm}$ are presented in the paper. However, it should be mentioned that similar values have been obtained in different engine running conditions with the straight duct as exhaust system.

\section{RESULTS AND DISCUSSION}

The predictions of the three heat transfer models using the current exhaust system geometry are presented in this section. It is important to remark that the same constants values obtained with the straight-duct exhaust system have been employed. Experimental information from three sources is used for models' assessment: the instantaneous pressure measured in locations \#1, \#2 and \#3 in the exhaust system, the delivery ratio and, finally, the engine BMEP.

Fig. 9 shows a matrix of plots containing the exhaust pressure traces in three engine speeds: 9500 (left column), 11500 (middle column) and $12500 \mathrm{rpm}$ (right column), and the different 
transducers locations: \#1 (top row), \#2 (middle row) and \#3 (bottom row). In each plot there is a comparison between the heat transfer models together with the measured data. It is important to remark that the parameters for the Nusselt correlation are the same as the presented before with the straight duct as exhaust pipe. Main differences appear at $12500 \mathrm{rpm}$ and location \#1 (top right plot). In this case the proposed model predicts with better accuracy the measured exhaust pressure than the other two models. This fact is observed in the prediction of the depression wave that occurs before BDC $(180 \mathrm{cad})$ and also in the pressure wave that remains in the exhaust system when the exhaust port is closed, as detected in the overpressure wave at $40 \mathrm{cad}$.

Although, in general terms, good predictions are observed for all heat transfer models concerning the instantaneous pressure profile in both amplitude and synchronization of pressure pulses, it is necessary to check the influence of the slight discrepancies on the engine scavenge process. Fig. 10 shows a matrix of plots containing two engine speeds: 9500 (left column) and $12500 \mathrm{rpm}$ (right column), and the calculated results in terms of: the instantaneous in-cylinder mass (top row), and the exhaust (middle row) and intake (bottom row) mass flows. A positive value of the mass flow means that the flow is coming out from the cylinder. Negative values occur when backflows appear. A typical situation is the exhaust mass flow going into the cylinder before closing the exhaust port due to the overpressure wave created in convergent pipe of the exhaust system.

Exhaust mass flows in Fig. 10 present remarkable differences between the different models in the period from BDC and the exhaust port closing. Slight discrepancies are also found in the same period for the intake mass flow. Both intake and exhaust mass flows configure the evolution of the in-cylinder mass, which can lead up to $20 \%$ variation in total trapped mass as observed in the top graphs. The differences in the exhaust mass flow evolutions in the period from port opening to BDC are not relevant between the three models since the exhaust process is dominated by the high values of the in-cylinder pressure during the expansion stroke. The intake mass flow mainly depends on the pressure difference between the crankcase and the cylinder and irrelevant differences are found until the piston arrives to the BDC. The influence of the exhaust pressure in the cylinder becomes important once the piston achieves the BDC. 
From this point exhaust heat transfer modelling provides significant differences in the predicted scavenge process.

As introduced in Fig. 3, comparisons of the predicted scavenging and trapping efficiencies are provided in Fig. 11. Each plot presents not only the absolute values but also the difference in percentage related to the proposed model. Top graph shows the scavenging efficiency. It is important to remark that the predicted values are between 0.9 and 1 , with very reduced differences among the three models. The design of a high-performance engine leads to minimize the residual gases from the previous engine cycle and, as other systems, the exhaust system geometry is conceived to promote an efficient extraction of the exhaust gases from the cylinder. On the other side, trapping efficiency values are in the range between 0.5 and 0.8 , which means that a large amount of the supplied fresh mixture becomes short-circuit mass, directly to the exhaust system without being burnt. Trapping efficiency increases with engine speed as the backflow created by the convergent pipe in the exhaust system and described in Fig. 10 is better synchronized with exhaust port closing. Besides the engine behaviour and the absolute values of the trapping efficiency, a relevant issue is the significant differences provided by the three exhaust heat transfer models. When compared to the proposed model, variations up to $10 \%$ are found in the Farrugia and Zeng models depending on the engine speed. These differences in the short-circuit prediction influence on the fuel trapped for the next engine cycle and lead to divergences in the predicted engine performance.

Fig. 12 compares the predicted results with measured data concerning delivery ratio (bottom) and brake mean effective pressure (top). Measurements are plotted in solid line and two gray zones are depicted too. Dark gray zone corresponds to points with variations less than $\pm 5 \%$, while the light gray zone includes errors up to $\pm 10 \%$. All the models predict with great accuracy the delivery ratio at 9500 and $11500 \mathrm{rpm}$. The majority of predicted values fall inside the $\pm 5 \%$ error zone. However, the model that accounts for entrance length (circle symbols) provides low values of supplied mass at lower engines speeds. On the contrary, the model that considers the velocity fluctuations (cross symbols) underestimate the mass flow at higher engine speeds. The proposed model provides good predictions for all the range of engine speeds.

The explanation to these cycle-averaged results is found in the instantaneous mass flow evolutions as shown for two engine speeds in Fig. 10. As an example, the supplied mass at 
$12500 \mathrm{rpm}$ is well captured by the proposed model while higher errors appear with the other two models. Analyzing in more detail the plots on the right of Fig. 10 (12500 rpm) it is detected that intake mass flow (bottom plot) is higher in the proposed model in the period after BDC. The reason to this higher intake mass flow is closely related with the exhaust mass flow (middle plot) evolution which, finally, is governed by the instantaneous pressure in the exhaust system (as illustrated in the differences found in the top right corner of Fig. 9).

An interesting result of the presented work is to analyze the influence that the discrepancies in the scavenging related parameters has in engine performance. Again, most of the predicted results show errors below $\pm 5 \%$ in terms of BMEP. The results from the proposed model correlate with great accuracy the measured data. The other two models present errors higher than $\pm 5 \%$ at different engine speeds. It should be mentioned that BMEP and delivery ratio results do not have to correlate since the trapping efficiency also influences on the BMEP.

\section{CONCLUSIONS}

The heat transfer in the exhaust system of high-performance two-stroke engines was investigated. Different models from the literature, which take into account the entrance length and the flow velocity fluctuations, together with a proposed one that combines the two phenomena, were included in the frame of a 1D engine simulation code.

A $125 \mathrm{cc}$ engine was tested under wide open throttle conditions in a fully instrumented engine test bench. Three pressure transducers were placed in the exhaust system to capture wave propagation phenomena. The calibration of the parameters of the three models was performed with engine tests using a straight pipe with constant transversal section as exhaust system. The constants values are valid for all the range of tested conditions.

Models assessment was carried out by comparing the predicted results with the measured exhaust pressure traces in three locations along the exhaust system. The slight differences found in the pressure signals are better analyzed when observing the predicted mass flows through the transfer and exhaust ports. Models comparison is finally performed by using scavenge process related parameters and the influence on BMEP.

Since this type of engines are designed for high performance operation, cylinder ports and exhaust system geometry are conceived to minimize the residual burnt gases that would remain 
inside the cylinder for the next engine cycle. Therefore, the scavenging efficiency predicted by the three models is higher than 0.9 and the differences between the models do not exceed $3 \%$. However, variations up to $12 \%$ are found when comparing the calculated trapping efficiency among the models.

Finally, the proposed model results in terms of delivery ratio and BMEP provide differences with measured data lower than $3 \%$ for the investigated range of engine speeds. However, the model that accounts for entrance length and the one that relies on the flow velocity fluctuations predict differences in the delivery ratio values between $5 \%$ and $10 \%$ at certain engine speeds. Similar conclusion is derived for the BMEP results. The combined heat transfer model is able to predict engine performance for a wide range of engine speeds although the number of calibration parameters is two for all the models.

\section{NOMENCLATURE}

b constant in Zeng's correlation

C source term vector

$\mathrm{C}_{1} \quad$ constant in Farrugia's correlation

$\mathrm{C}_{2}$ constant in Zeng's correlation

d constant in Farrugia's correlation

D diameter

F flux vector

g friction

h heat transfer coefficient

k thermal conductivity

$\mathrm{Nu} \quad$ Nusselt number

p pressure

$\operatorname{Pr} \quad$ Prandtl number

q heat

Re Reynolds number

$\mathrm{S}$ cross section

t time 


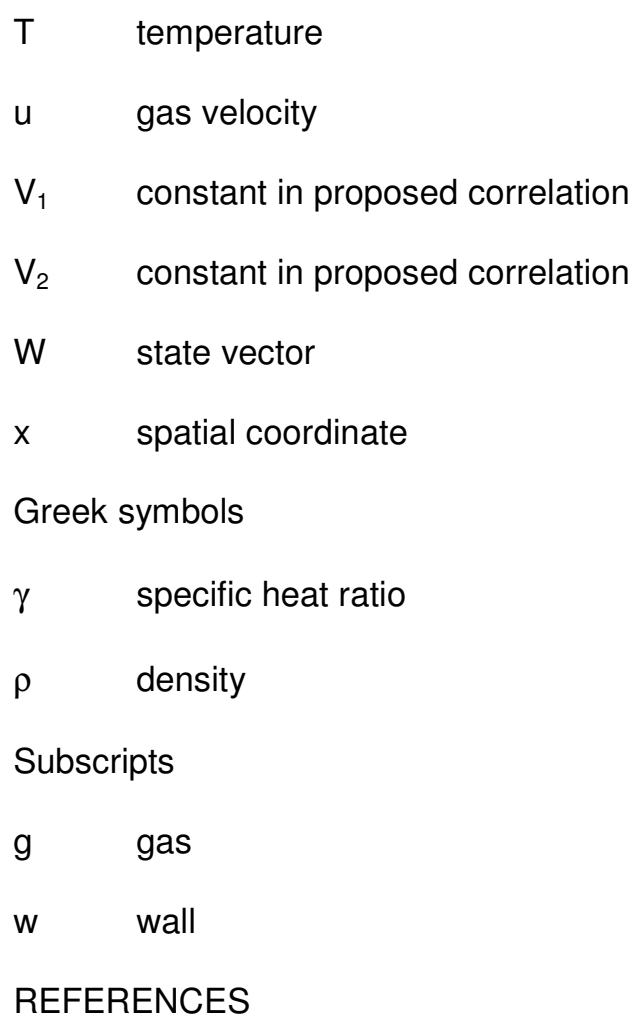

[1]. J. Galindo, J.R. Serrano, H. Climent, A. Tiseira, Analysis of gas-dynamic effects in compact exhaust systems of small two-stroke engines, International Journal of Automotive Technology 8 (N4) (2007) 403-411.

[2]. F.W. Dittus, L.M.K. Boelter, Heat transfer in automobile radiators of the tubular type. University of California, Berkley Publications on Engineering 2 (13) (1930) 443-461.

[3]. E.N. Sieder, G. E. Tate, Heat transfer and pressure drop of liquids in tubes, Ind. Eng. Chem. 28 (12) (1936) 1429-1435.

[4]. E.W. Huber, T. Koller, Pipe Friction and Heat Transfer in the Exhaust Pipe of a Firing Combustion Engine, Proceedings of the CIMAC Convention, Tokio, (1977) 2075-2105.

[5]. D.W. Wendland, Automobile Exhaust-System Steady-State Heat, SAE Paper (1993) 931085.

[6]. P.J.Shayler C.M. Harb, T. Ma, Time-Dependent Behaviour of Heat Transfer Coefficients for Exhaust Systems, IMechE Paper C496/046/95, VTMS 2 Conf. Proc., 1995.

[7]. C. Depcik D. Assanis, A Universal Heat Transfer Correlation for Intake and Exhaust Flows in a Spark-Ignition Internal Combustion Engine, SAE Paper (2002) 2002-01-0372. 
[8]. E.A.M. Elshafei, M. Safwat Mohamed, H. Mansour, M. Sakr, Experimental study of heat transfer in pulsating turbulent flow in a pipe, International Journal of Heat and Fluid Flow 29 (4) (2008) 1029-1038.

[9]. J. Benajes, A.J., Torregrosa, M. Reyes, Heat Transfer Model for I.C. Engine Exhaust Manifolds, Proc. Seminair Eurotherm 15 Transferts de Chaleur dans le Moteurs a Combustion Interne, Tolouse, 1991.

[10]. W.D. Bauer, J. Wenisch, J.B. Heywood, Averaged and time-resolved heat transfer of steady and pulsating entrance length flow in intake manifolds of a spark-ignition engine, International Journal of Heat and Fluid Flow 19 (1998) 1-9.

[11]. M. Farrugia, A.C. Alkidas, P. Sangeorzan, Cycle-Average Heat Flux Measurements in a Straight-Pipe Extension of an Exhaust Port of an SI Engine, SAE Paper (2006) 2006-01-1033.

[12]. A. Sorin, F. Bouloc, B. Bourouga, P. Anthoine, Experimental study of periodic heat transfer coefficient in the entrance zone of an exhaust pipe, International Journal of Thermal Sciences 47 (2008), 1665-1675.

[13]. N. Balzan, B.P. Sangeorzan, A.C. Alkidas, Steady-State Local Heat Flux Measurements in a Straight-Pipe Extension of an Exhaust Port of a Spark Ignition Engine, SAE Paper (2007) 2007-01-3990.

[14]. P. Zeng, D.N. Assanis, Unsteady convective heat transfer modeling and application to engine intake manifolds, Proceedings of the ASME International Mechanical Engineering Congress and R\&D Expo (2004) Paper 2004-60068.

[15]. J. Galindo, J.R. Serrano, F.J. Arnau, P. Piqueras, Description of a Semi-Independent Time Discretization Methodology for a One-Dimensional Gas Dynamics Model, Journal of Engineering for Gas Turbines and Power 131 (3) (2009).

[16]. J. Galindo, H. Climent, B. Pla, V.D. Jiménez, Correlations for Wiebe Function Parameters for Combustion Simulation in Two-Stroke Small Engines, Applied Thermal Engineering, 31 (2011) 1190-1199.

[17]. F. Payri, J.M. Desantes, A.J. Torregrosa, Acoustic boundary conditions for unsteady one-dimensional flow calculations, Journal of Sound and Vibration, 188 (1) (1995) $85-110$. 
[18]. F. Payri, J.M. Desantes, A. Broatch, Modified impulse method for the measurement of the frequency response of acoustic filters to weakly nonlinear transient excitations, Journal of the Acoustic Society of America, 107 (2) (2000) 731-738.

[19]. H. Daneshyar, One-Dimensional Compressible Flow, Oxford, Pergamon Press, Ltd., 1976.

[20]. D.E. Winterbone, R.J. Pearson, A Solution of the Wave Equations Using Real Gases, International Journal of Mechanical Sciences 34 (N12) (1992) 917-932.

[21]. A. Harten, High resolution schemes for hyperbolic conservation laws, Journal of Computational Physics, 49 (3) (1983) 357-393.

[22]. G.P. Blair, Design and simulation of two-stroke engines, R-161 Society of Automotive Engineers, Inc. Warrendale, PA. 1995.

[23]. V.Macián, B. Tormos, P. Olmeda, R.W. Peralta, Fault detection in diesel engines using infrared thermography Insight, 44 (2002) 228-232..

[24]. J. Benajes, V. Bermúdez, H. Climent, M.E. Rivas-Perea, Instantaneous pressure measurement in pulsating high temperature internal flow in ducts, Applied Thermal Engineering, 61 (2013) 48-54.

[25]. N. Ozdor, M. Dulger, E. Sher, Cyclic Variability in Spark Ingnition Engines A Literature Survey, SAE Paper (1994) 940987. 
TABLES

\begin{tabular}{|l|l|}
\hline Engine displacement: & $125 \mathrm{~cm}^{3}$ \\
\hline Cylinders: & 1 \\
\hline Bore: & $54 \mathrm{~mm}$ \\
\hline Stroke: & $54.5 \mathrm{~mm}$ \\
\hline Transfer ports: & 5 \\
\hline Exhaust ports: & $1(+2)$ \\
\hline Transfer ports opening: & $113^{\circ}$ aTDC \\
\hline Exhaust ports opening: & $83^{\circ}$ aTDC \\
\hline Crankcase inlet control: & Rotating disk \\
\hline Fuel supply system: & Carburettor \\
\hline
\end{tabular}

Table 1. Engine main characteristics.

\begin{tabular}{|l|l|l|}
\hline Model & Parameter & Range \\
\hline Farrugia & $\mathrm{C}_{1}$ & $0.5-4$ \\
\hline & $\mathrm{d}$ & $0.1-1$ \\
\hline Zeng & $\mathrm{C}_{2}$ & $0.4-5$ \\
\hline & $\mathrm{b}$ & $0.4-1$ \\
\hline Proposed & $\mathrm{V}_{1}$ & $1-16$ \\
\hline & $\mathrm{V}_{2}$ & $0.4-1$ \\
\hline
\end{tabular}

Table 2. Simulation matrix for heat transfer models calibration. 
FIGURES

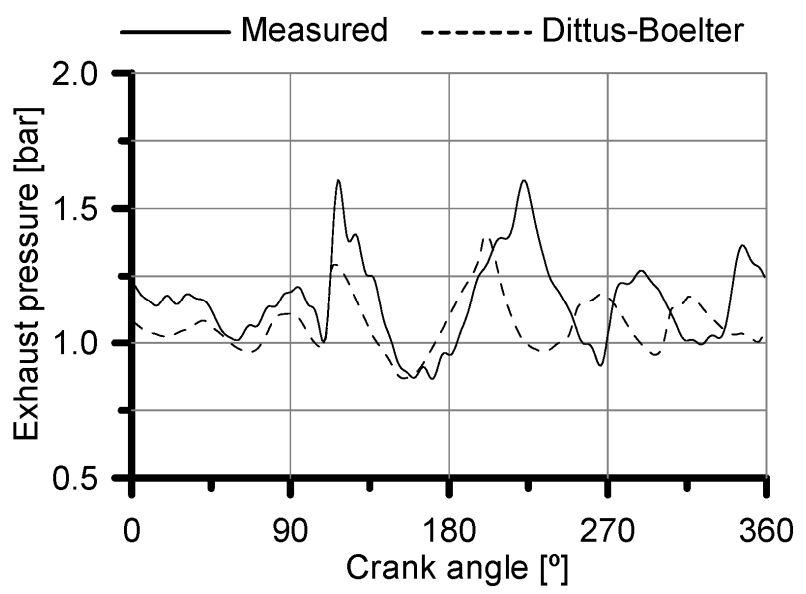

Fig 1. Exhaust port instantaneous pressure at $12500 \mathrm{rpm}$ and full load: measured (solid line) and calculated (dashed line) with Dittus-Boelter correlation.

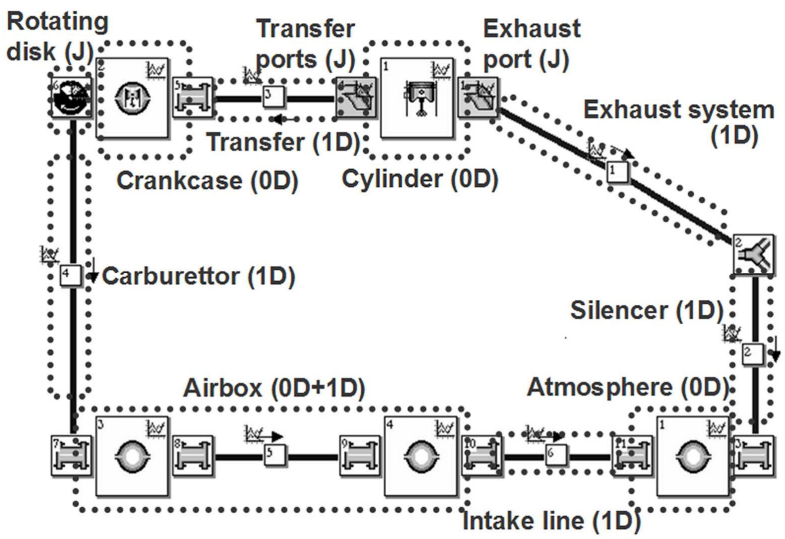

Fig 2. Schematic layout of the 1D engine model.

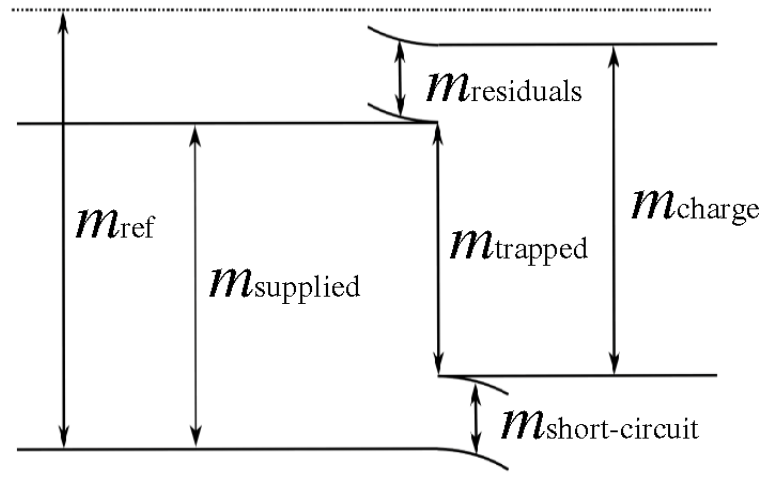

Fig 3. Masses definition for scavenge process evaluation. 


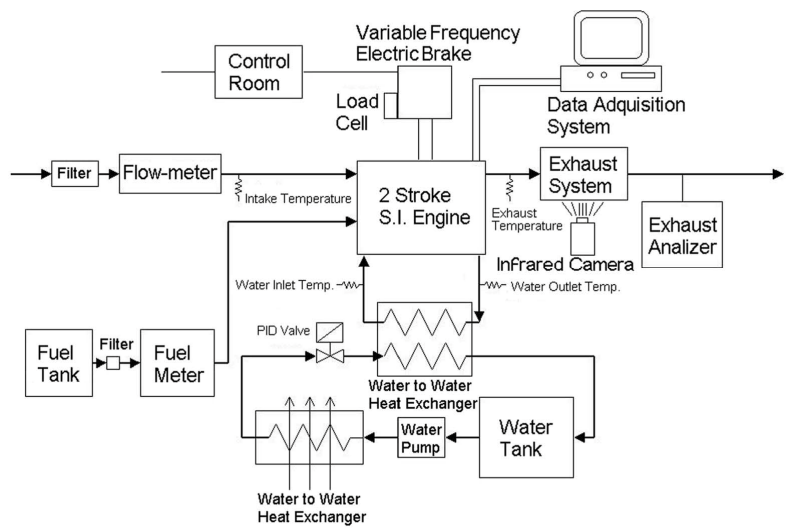

Fig 4. Schematic layout of the engine test bench.
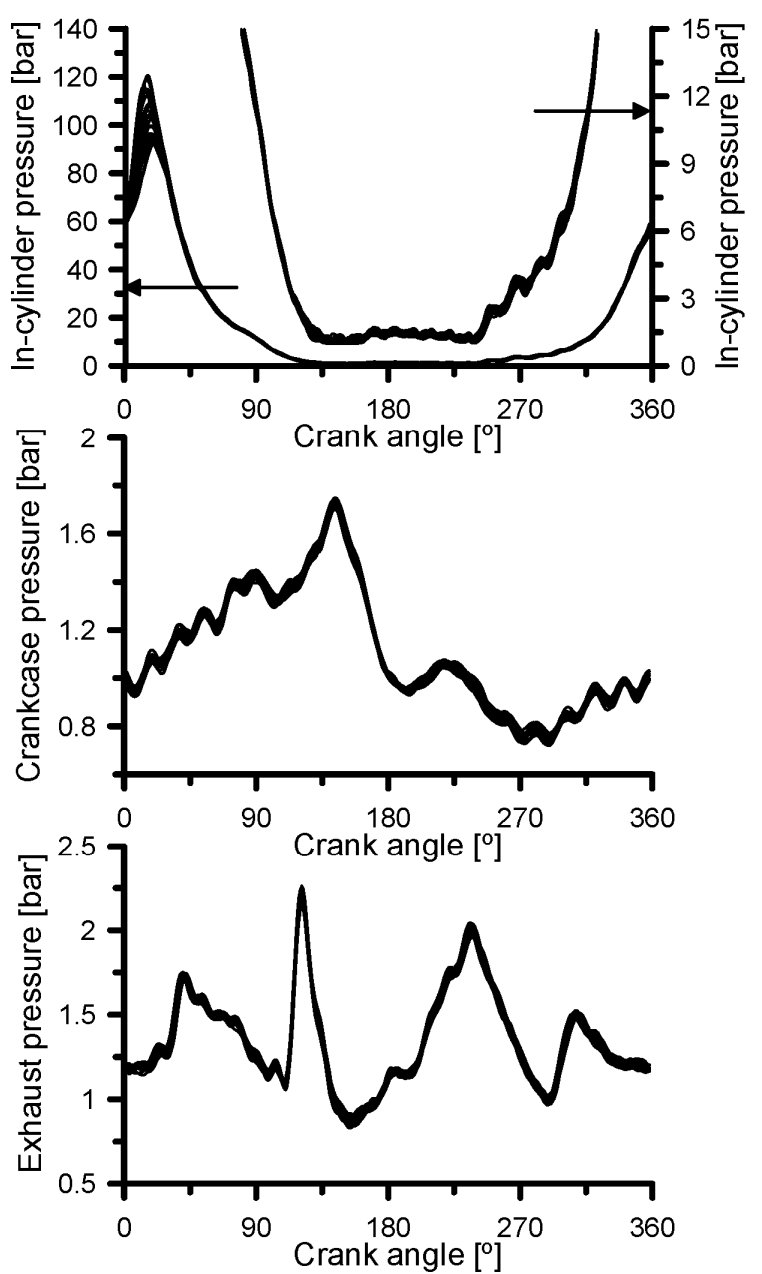

Fig 5. Cycle-to-cycle pressure variations in the cylinder (top), crankcase (middle) and exhaust system (bottom) at $12500 \mathrm{rpm}$.

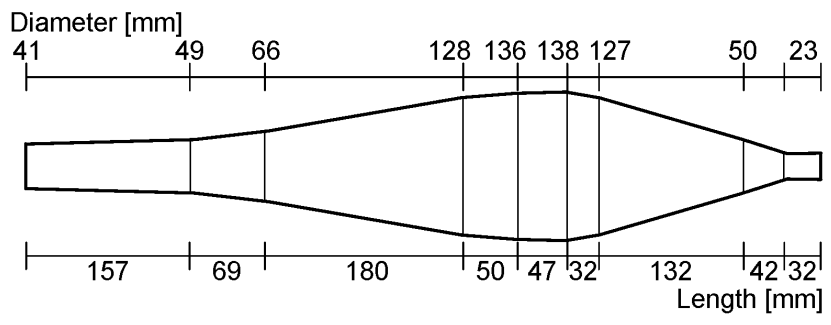

Fig 6. Schematic layout of the $125 \mathrm{cc}$ engine exhaust system. 

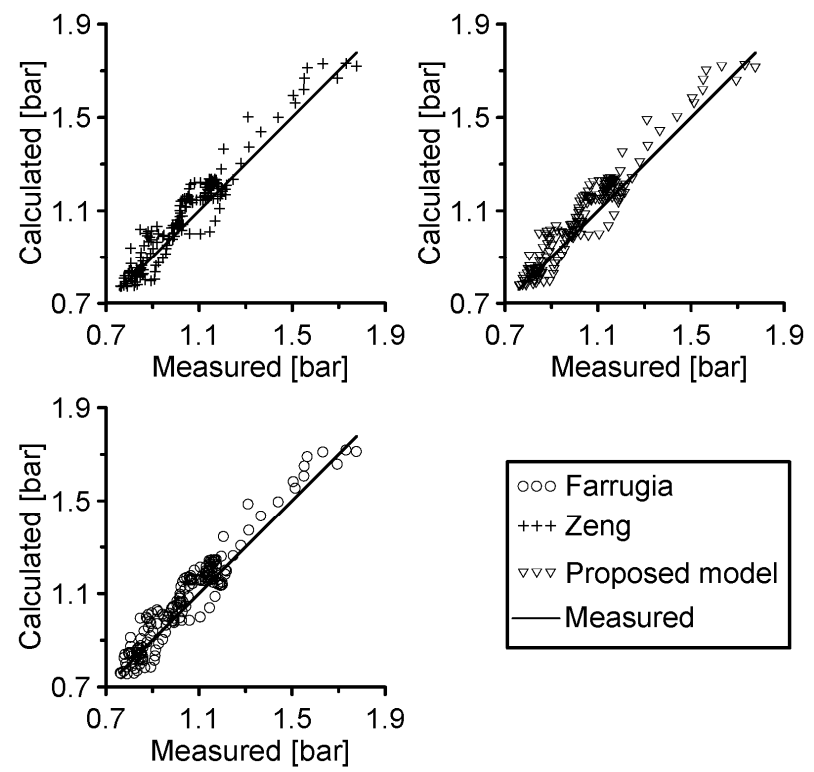

Fig 7. Comparison between measured and calculated exhaust pressure with the straight duct as exhaust system at $10500 \mathrm{rpm}$. 

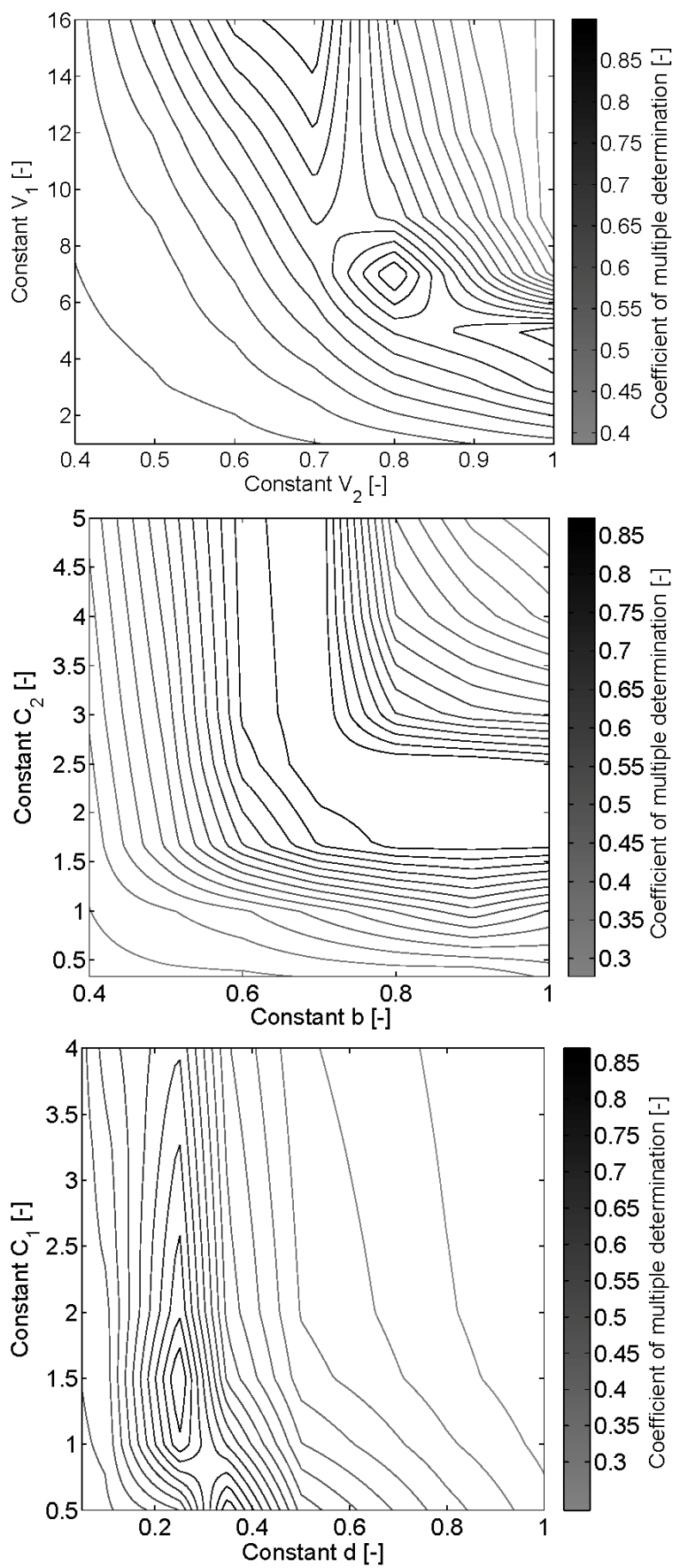

Fig 8. Coefficient of determination in the parameters calibration process at $10500 \mathrm{rpm}$ for the heat transfer models: proposed (top), Zeng (middle) and Farrugia (bottom). 


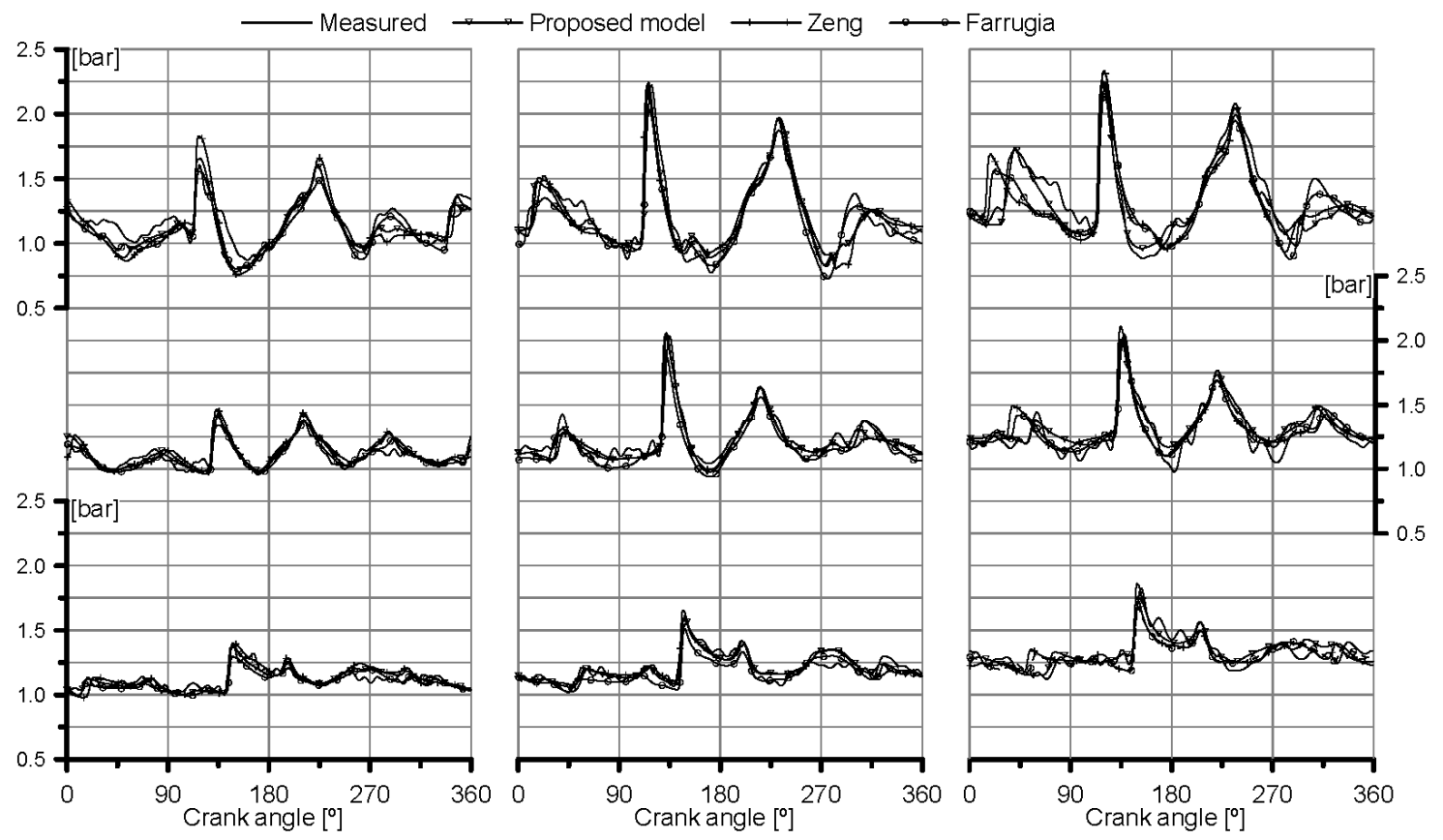

Fig 9. Measured and calculated instantaneous exhaust pressure in transducers \#1 (top), \#2 (middle) and \#3 (bottom) at 9500 (left), 11500 (middle) and 12500 rpm (right).

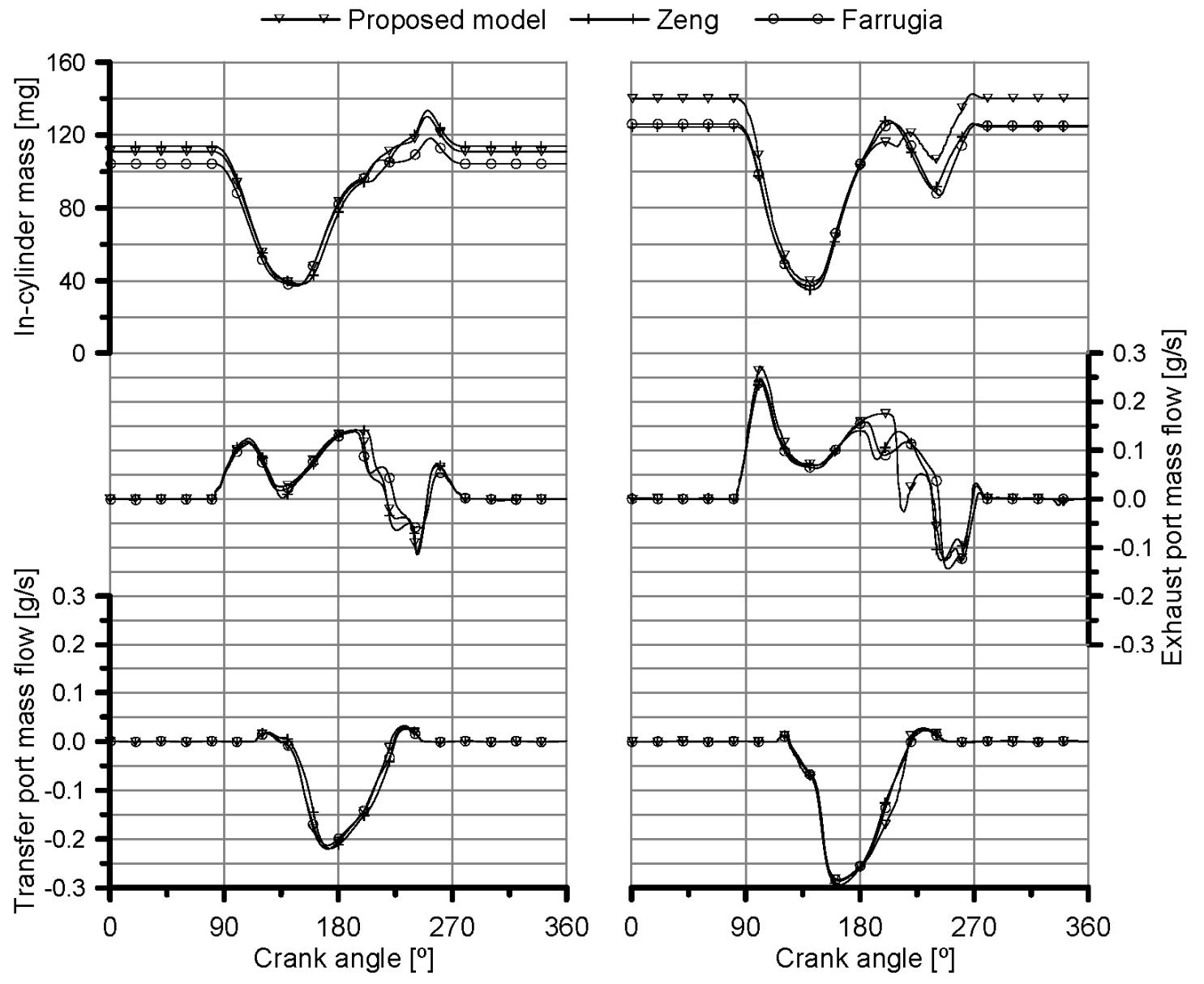

Fig 10. Calculated instantaneous in-cylinder mass (top) and, exhaust (middle) and intake (bottom) mass flows at 9500 (left) and 12500 rpm (right). 

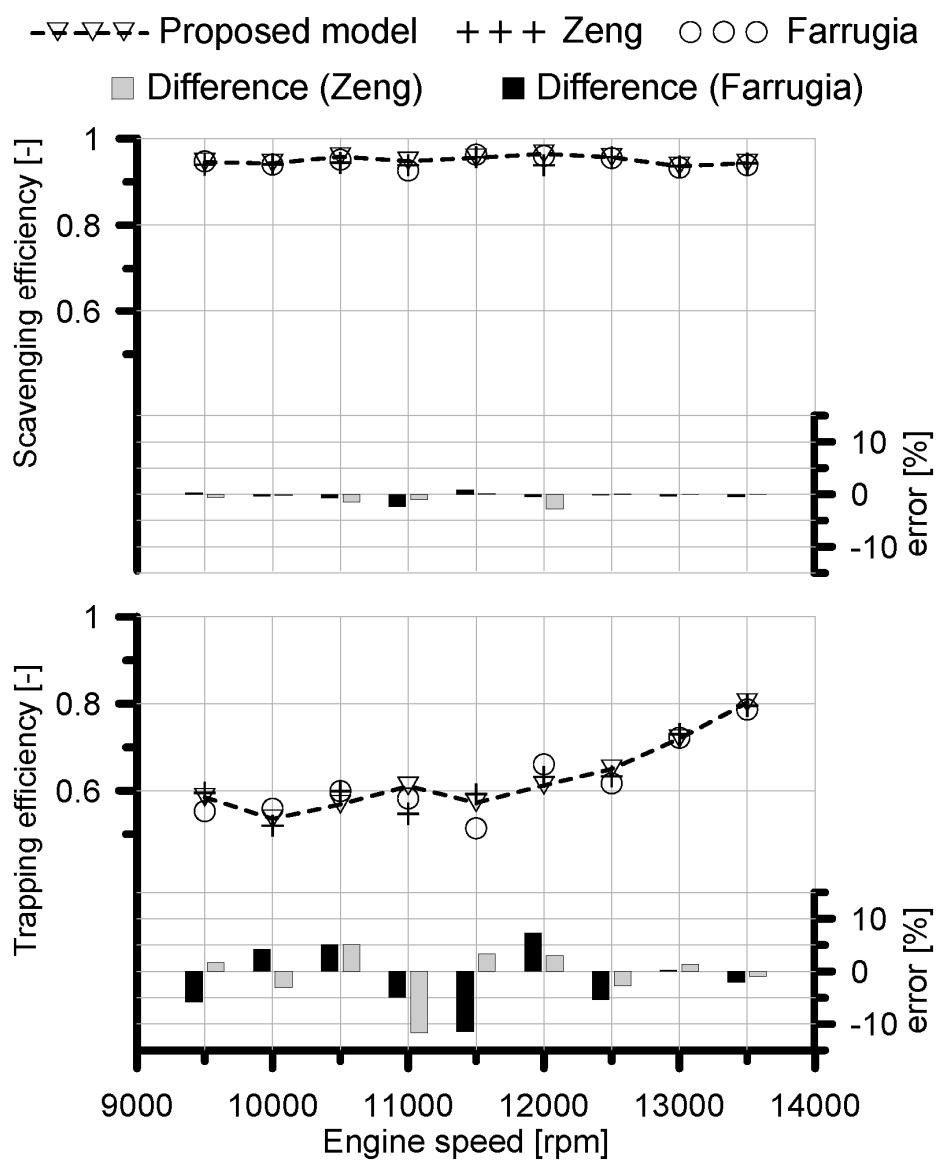

Fig 11. Calculated scavenging efficiency (top) and trapping efficiency (bottom).
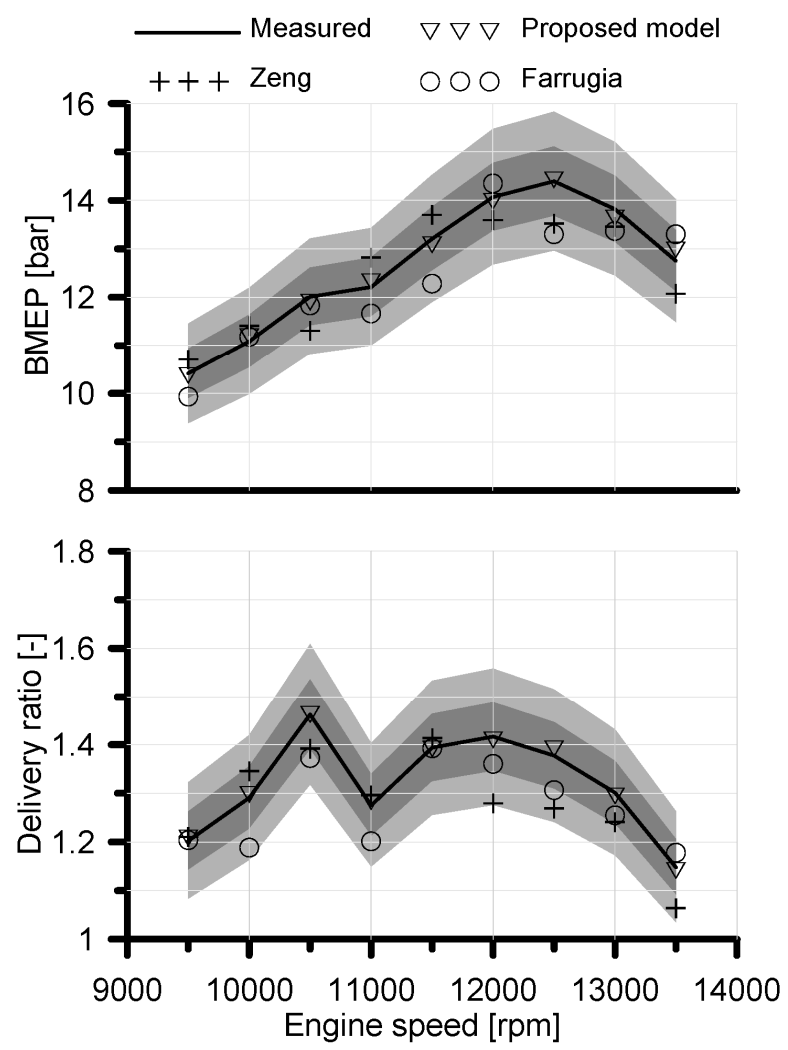

Fig 12. Measured and calculated BMEP (top) and delivery ratio (bottom). 